To study the mechanism of periodic paralysis, we investigated the properties of intact muscle fibers biopsied from a patient who had adynamia episodica hereditaria with electromyographic signs of myotonia. When the potassium concentration in the extracellular medium, $[\mathrm{K}]_{\mathrm{e}}$, was $3.5 \mathrm{mmol} / \mathrm{l}$, force of contraction, membrane resting potential, and intracellular sodium activity were normal, but depolarizing voltage clamp steps revealed the existence of an abnormal inward current. This current was activated at membrane potentials less negative than $-80 \mathrm{mV}$, reached a maximum within $50 \mathrm{msec}$, and was not inactivated with time. The inward current was completely and reversibly blocked by tetrodotoxin, which indicates that it was carried by sodium ions. In a solution containing $9 \mathrm{mmol} / \mathrm{l}$ potassium, normal muscle would depolarize to $-63 \mathrm{mV}$ and yet be capable of developing full tetanic force upon stimulation. The muscle from the patient depolarized to $-57 \mathrm{mV}$ and became inexcitable, i.e., it was paralyzed. A contracture did not develop. Lowering of the extracellular $\mathrm{pH}$ did not influence the resting potential, but it effectively antagonized or prevented the paralytic effect of high $[\mathrm{K}]_{e}$ by changing the inactivation characteristics of the sodium channels. Hydrochlorothiazide, which had a therapeutic effect on the patient, did not prevent paralysis in vitro. An abnormal rise of the intracellular sodium activity was recorded when the extracellular potassium concentration was raised to 10 $\mathrm{mmol} / \mathrm{l}$.

MUSCLE \& NERVE $\quad 10: 363-374$

1987

\title{
ADYNAMIA EPISODICA HEREDITARIA WITH MYOTONIA: A NON-INACTIVATING SODIUM CURRENT AND THE EFFECT OF EXTRACELLULAR PH
}

\author{
FRANK LEHMANN-HORN, MD, GERALD KÜTHER, MD, KENNETH RICKER, MD, \\ PETER GRAFE, MD, KLAUS BALLANYI, PhD, and REINHARDT RÜDEL, PhD
}

\begin{abstract}
Adynamia episodica hereditaria, first described in $1955,{ }^{15}$ is a rare muscle disease with autosomal dominant inheritance. Clinically it is similar to the much more common hypokalemic periodic paralysis; however, during episodes of muscle weakness the serum potassium rises rather than falls. The
\end{abstract}

From the Neurologische Klinik und Poliklinik der Technischen Universität München, West Germany (Drs. Lehmann-Horn and Küther), the Neuro!ogische Universitätsklinik Würzburg, West Germany (Dr. Ricker), the Physiologisches Institut der Ludwig Maximilian Universität München, West Germany (Drs. Grafe and Ballanyi), and the Abteilung fur Algemeine Physiologie der Universität Ulm, West Germany (Dr. Rüdel).

Acknowledgments: We are grateful to Prof. H.G. Mertens for referring the patient to us, to Dr. H.W. Präuer for help with surgery, and to Ms. E. Höhne for technical assistance. Supported by the Deutsche Forschungsgemeinschaft (Le 481/1-2), the Deutsche Geselischaft Bekämpfung der Muskelk rankheiten (K.R.), and the Wilhelm Sander Stiftung (P.G.).

Address reprint requests to Dr. F. Lehmann-Horn at the Neurologische Klinik und Poliklinik der Technischen Universität München, Möhlstr. 28, D-8000 München, West Germany.

Received for publication January 6,1986 ; revised manuscript accepted for publication June 20, 1986.

0148-639X/1004/0363 \$04.00/12

1987 John Wiley \& Sons, Inc. disease, therefore, is also often called hyperkalemic periodic paralysis. We prefer the original name given to it by Gamstorp, ${ }^{12}$ because the attacks occur episodically with no recognizable periodicity and are usually characterized by muscle weakness-adynamia-rather than by complete paralysis. Moreover, the name adynamia episodica is better suited to point out the genetic and pathophysiological distinction from hypokalemic periodic paralysis. ${ }^{33}$

Three variants of adynamia episodica have been described: (1) in combination with clinical or electromyographical myotonia, ${ }^{6,8,18,19,24-26,28,31}$ (2) without any signs of myotonia, ${ }^{3,+416,24,27}$ and (3) in combination with paramyotonia. ${ }^{2,10,11,29,30}$ The latter variant has also been called paralysis periodica paramyotonica. ${ }^{2.30}$ The affected members of a given family always show the same variant.

In a previous study some of us have reported the membrane and contraction parameters of a patient with variant (1) and a patient with variant (2). ${ }^{24}$ The membrane parameters of a patient with variant (3) were reported in a study on paramy- 
otonia congenita ${ }^{2 \cdot 3}$ at a time when we were not aware of this patient's episodic attacks of work- or potassium-induced weakness (case "PWMD"). (In the meantime, an extensive report has been published describing the clinical differentiation of adynamia and paranyotonia in this patient and the selective treatment of the two symptoms by the use of different drugs. $\left.{ }^{29}\right)$ As a major result of these first studies, ${ }^{23,2-4}$ each of the three clinical variants was characterized by different abnormalities in the electrophysiological parameters. But since these differentiations were based on one patient for each variant only, more investigations seemed necessary. We now describe further in vitro experiments with intact muscle fibers biopsied from another adynamia patient with variant (1). The new results confirm the earlier finding ${ }^{24}$ that adynamia episodica is related to an abnormal sodium conductance of the muscle fiber membranes and characterize the voltage and time dependence of this conductance. Additional experiments were performed to study in vitro the effect of low extracellular $\mathrm{pH}$ on muscle paralysis.

A clinical study of this patient has appeared."3) Part of the results have been presented to the German Physiological Society. ${ }^{13}$

\section{MATERIAL AND METHODS}

The study was approved by the Ethics Commission of the Technical University of Munich and was carried out in abidance with the Helsinki convention. The patient, a 22-year-old woman of athletic constitution (case 1 of Ricker et al. ${ }^{3 n}$ ) has suffered from attacks of adynamia from her late teens on, as has her younger brother. During rest after work on a bicycle ergometer, her serum potassium would rise to $>7 \mathrm{mmol} / \mathrm{l}$, causing severe muscle weakness. She has never experienced muscle stiffness in connection with adynamia, but lid lag and myotonic runs in the EMG were clearly present between attacks. The patient gave informed consent for an external intercostal muscle biopsy to be taken. The specimen was obtained under general anesthesia without the use of muscle relaxants. Small muscle fiber bundles were dissected for the measurements of contraction force, membrane parameters, and the intracellular $\mathrm{Na}$ activity. Control values of normal human intercostal muscle that were not available from references ${ }^{20,21}$ were measured in a muscle specimen from a patient without muscle disease who had to undergo thoracic surgery.

For the measurement of contraction force, a bundle containing about 500 fibers was suspended in a plexiglass chamber with one end fixed and the other end fastened to a quasi-isometric semiconductor strain gauge. The length of the bundle was so adjusted that the force during tetanic stimulation was maximal. A silver wire ran along either side of the preparation for direct ("massive field") stimulation. Supramaximal square current pulses of 0.2 msec duration were applied as 300 -msec trains of $50 \mathrm{~Hz}$ frequency at intervals of at least 5 minutes.

For the measurement of membrane parameters and current-voltage relationships, the voltage clamp set-up and the experimental protocol were used as already described. ${ }^{23}$ Data analysis was carried out off-line with the use of a PDP 1 1/23 computer (Digital Equipment Corporation, Maynard, MA). ." $^{32}$

For the determination of the availability of the sodium current, the fibers were impaled with two microelectrodes at a distance of $\sim 100 \mu \mathrm{m}$. DC currents were applied through one electrode so that the membrane potential, measured through the other electrode, assumed holding values between -120 and $-50 \mathrm{mV}$ (in $10 \mathrm{mV}$ steps). When the holding potential had been maintained for $>10(0) 0$ msec, a brief ( $1-3 \mathrm{msec})$ depolarizing pulse was applied through the current electrode so that an action potential was elicited. 'The rate of rise of this action potential was obtained by electronic differentiation. The maximum rate of risc, plotted against the holding potential, gives a measure of the availability of the sodium channels (" $h_{x}$ curve").

The determination of the intracellular sodium activity $\left(\mathrm{aNa}_{\mathrm{i}}\right)$ of the muscle fibers was carried out with a set-up described elsewhere. ${ }^{1.1}$ Na-sensitive microelectrodes were made from double-barrelled glass pulled to a tip diameter of $0.5 \mu \mathrm{m}$. One barrel was filled with a "Na cocktail" (71176, Fluka, NeuUlm, West Germany), the other one with $1 \mathrm{~mol} / \mathrm{l}$ magnesium acetate.

Solutions. The standard solution ${ }^{5}$ used for transportation, dissection, and basic experiments contained (in mmol/l): $\mathrm{NaCl}, 107.7 ; \mathrm{KCl}, 3.48 ; \mathrm{CaCl}$, 1.53; $\mathrm{MgSO}_{4}, 0.69 ; \mathrm{NaHCO}_{3}, 26.2 ; \mathrm{NaH}_{2} \mathrm{PO}_{4}, 1.67$, sodium gluconate, 9.64; saccharose, 7.6; glucose, 5.5 . The $\mathrm{pH}$ was set at 7.4 by gassing this solution with carbogen (a mixture of $5 \% \mathrm{CO}_{2}$ and $95 \%\left(\mathrm{O}_{2}\right.$ ). Solutions with higher than normal potassium concentrations were obtained by the addition of the appropriate amounts of $\mathrm{KCl}$ to the standard solution.

For the blockade of the sodium channels, tetrodotoxin (T TX, Roth, Karlsruhe, West Germany or Sigma, München, West (Eermany) was used. In some experiments the $\mathrm{pH}$ of the solutions was low- 
ered to about 6.5 , either by gassing the solution with a mixture of $40 \% \mathrm{CO}_{2}$ and $60 \% \mathrm{O}_{2}$ or by the addition of the appropriate amount of $\mathrm{HCI}$. Hydrochlorothiazide (Esidrix, CIBA-Geigy, Wehr, West Germany), when present, was at $0.125 \mathrm{mmol} / \mathrm{l}$, and ouabain (Sigma) was at $0.3 \mathrm{mmol} / \mathrm{l}$.

All experiments were conducted at $37^{\circ} \mathrm{C}$. Results are given as mean values $\pm \mathrm{SD}$.

\section{RESULTS}

Contraction Measurements and the Effect of Low pH. In the standard solution, the twitches and tetani of the bundles were of normal force amplitude. When the extracellular potassium concentration, $[\mathrm{K}]_{e}$, was raised to $7 \mathrm{mmol} / \mathrm{l}$, the contraction force decreased similar to the way it does in vivo during hyperkalemia. When at that stage the bathing solution was gassed with $40 \% \mathrm{CO}_{2}$, the extracellular $\mathrm{pH}$ quickly decreased to 6.5 , and the force recovered (Fig. 1) although $[\mathrm{K}]_{\mathrm{e}}$ was still at $7 \mathrm{mmol} / \mathrm{l}$. When the solution was gassed again with normal carbogen, the force amplitude decreased. This decrease was very much accelerated when $[\mathrm{K}]_{\mathrm{e}}$ was raised slightly more, to $9 \mathrm{mmol} / \mathrm{l}$. When the $9-\mathrm{mmol} / \mathrm{l}-[\mathrm{K}]_{e}$ solution was gassed with $40 \% \mathrm{CO}_{2}$, the force amplitude recovered quickly, and when finally $[\mathrm{K}]_{\mathrm{e}}$ was lowered to the normal $3.5 \mathrm{mmol} / \mathrm{l}$, the force amplitude returned to $100 \%$.

To investigate whether this protection from paralysis was caused by extracellular acidity, we also lowered the $\mathrm{pH}$ by the addition of $\mathrm{HCl}$ to the bathing solution, keeping the $\mathrm{CO}_{2}$ concentration constant. Figure 2 shows an experiment in which the $\mathrm{pH}$ was lowered to 6.5 by $\mathrm{HCl}$ before $[\mathrm{K}]_{e}$ was raised to $9 \mathrm{mmol} / \mathrm{l}$. Under these conditions the contraction force did not decrease. When a bathing solution with $9 \mathrm{mmol} / 1[\mathrm{~K}]_{\mathrm{e}}$ and $\mathrm{pH} 7.4$ was flushed into the muscle bath, complete paralysis set in very
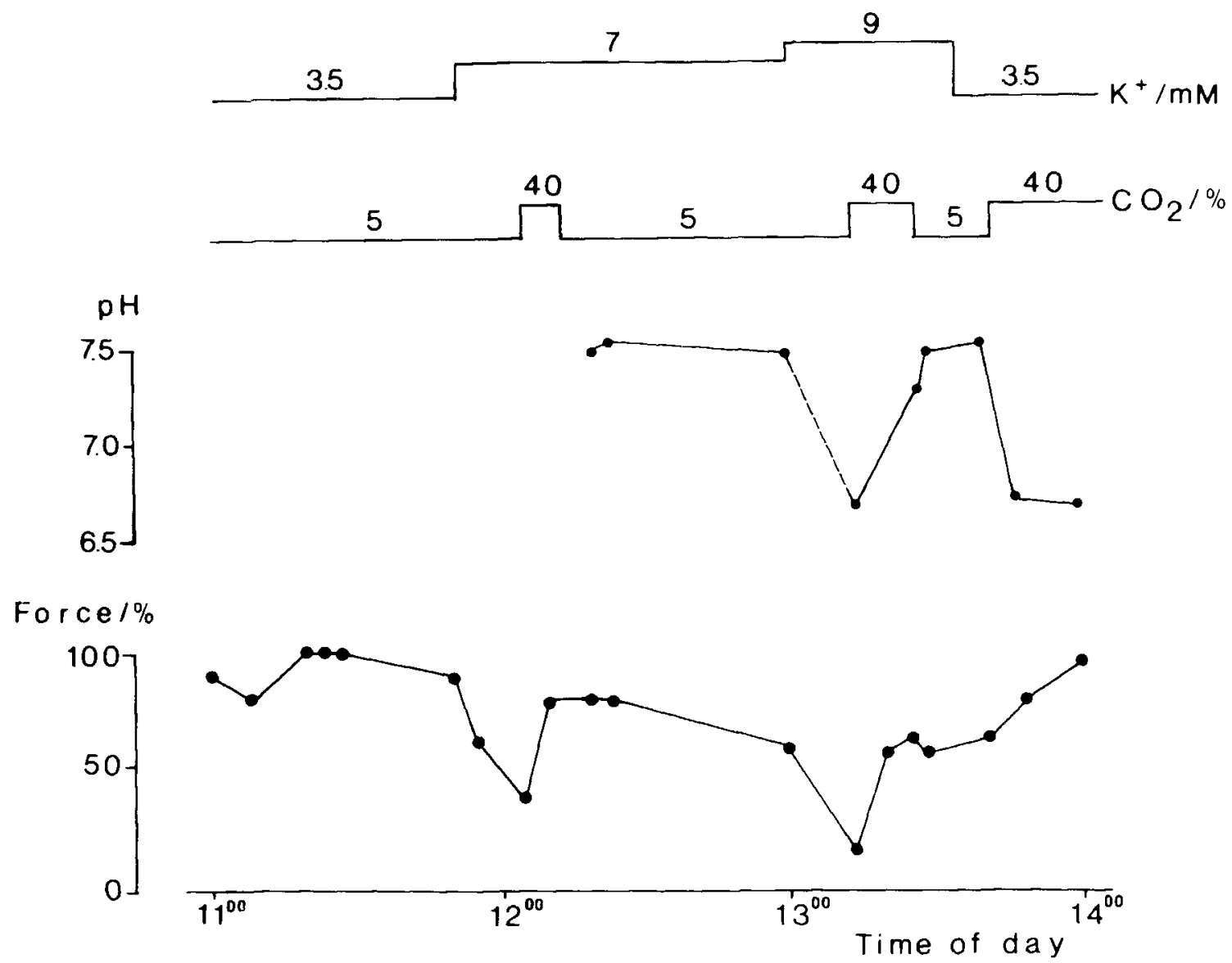

FIGURE 1. Maximal isometric force of tetanic contractions of a muscle bundle from the adynamia patient. The force decreases when the extracellular potassium concentration is raised and increases again when the high-potassium solution is gassed with a mixture of $40 \% \mathrm{CO}_{2}$ and $60 \% \mathrm{O}_{2}$. The $\mathrm{pH}$ in the muscle bath was measured with a glass electrode. Dashed Line: the change in pH occurred after the increase in $\mathrm{CO}_{2}$. 

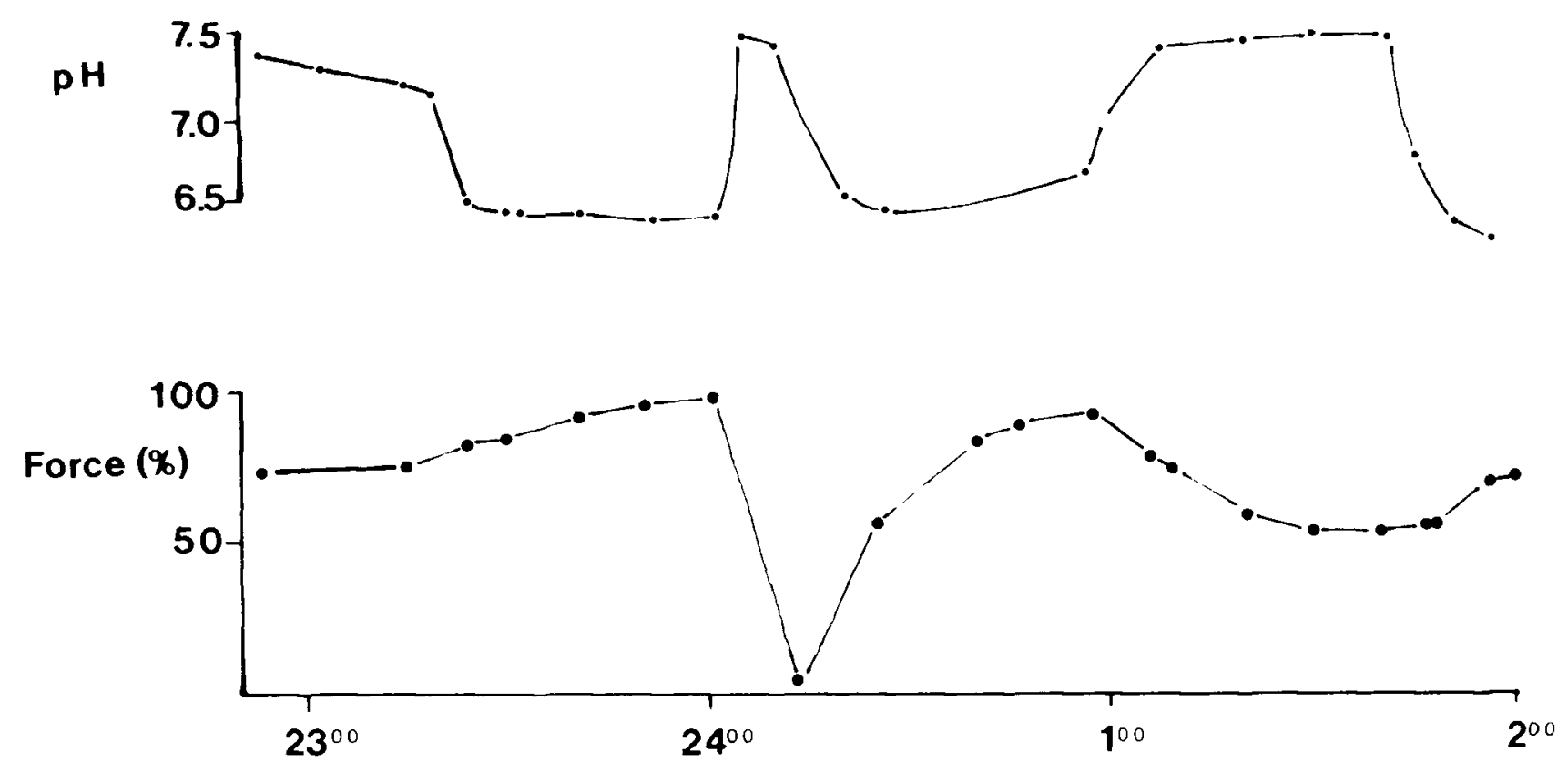

Time of day

FIGURE 2. Maximal isometric force of tetanic contractions as in Fig. 1 but with another bundie from the patient. The extracellular pH is lowered by the addition of $\mathrm{HCl}$ to the bathing fluid. This prevents the decrease of force on increase of $[\mathrm{K}]_{\mathrm{e}}$. When a high- $[\mathrm{K}]_{\mathrm{e}}$ solution with normal $\mathrm{pH}$ is flushed into the bath, the muscle becomes paralyzed. When the $\mathrm{pH}$ is lowered to 6.5 , the force recovers.

quickly, demonstrating the protective effect of a low $\mathrm{pH}$. Again, this effect was completely reversible.

Hydrochlorothiacide (HCT) prevents paralytic attacks in adynamia patients. ${ }^{26}$ To test whether the drug has a direct effect on the muscle fibers or acts perhaps via its well-known systemic effect of lowering the serum potassium, we did a similar ex-

Table 1. Resting potentials and membrane conductances of external intercostal muscle fibers from the patient with adynamia episodiaca hereditaria and from a healthy control person. Measurements were made in solutions containing 3.5 or $10 \mathrm{mmol} / \mathrm{l}$ potassium, with or without $0.3 \mathrm{mg} / \mathrm{TTX}$, and that were gassed with $5 \%$ or $40 \% \mathrm{CO}_{2}$ (means $\pm \mathrm{SD}$; number of fibers investigated in parentheses).

\begin{tabular}{|c|c|c|c|c|}
\hline \multirow[b]{2}{*}{ Solution } & \multicolumn{2}{|c|}{ Resting potential (mV) } & \multicolumn{2}{|c|}{$\begin{array}{l}\text { Membrane conductance }\left(\mu \mathrm{S} / \mathrm{cm}^{2}\right) \\
\text { at resting potential }\end{array}$} \\
\hline & Patient & Control & Patient & Control \\
\hline $\begin{array}{l}3.5 \mathrm{mMK} \\
5 \% \mathrm{CO}_{2}\end{array}$ & $-83.5 \pm 5.4(14)$ & $-80.2 \pm 2.4(9)$ & $110 t \pm 12(3)$ & $165 \pm 25(9)$ \\
\hline $\begin{array}{l}3.5 \mathrm{mM}^{-}+\mathrm{TTX} \\
5 \% \mathrm{CO}_{2}\end{array}$ & $-85.8 \pm 3.2(7)$ & $-81.4 \pm 3.2(7)$ & $183 \pm 23(7)$ & $158 \pm 28(6)$ \\
\hline $\begin{array}{l}9.0 \mathrm{mMK} \\
5 \% \mathrm{CO}_{2}\end{array}$ & $-57.3^{\star} \pm 5.4(30)$ & $-62.8 \pm 1.9(21)$ & $108 \dagger \pm 41(8)$ & $337 \pm 41(6)$ \\
\hline $\begin{array}{l}9.0 \mathrm{mMK}+\mathrm{TTX} \\
5 \% \mathrm{CO}_{2}\end{array}$ & $-67.5^{*} \pm 3.7(13)$ & $-64.8 \pm 4.8(14)$ & $376 \pm 69(6)$ & $321 \pm 46(6)$ \\
\hline $\begin{array}{l}9.0 \mathrm{mMK} \\
40 \% \mathrm{CO}_{2}\end{array}$ & $-58.5 \pm 3.1(29)$ & $-62.0 \pm 2.7(7)$ & $137 \dagger \pm 42(5)$ & $341 \pm 38(7)$ \\
\hline
\end{tabular}

"The difference of the resting potential values (in $9 \mathrm{mM} \mathrm{K}$ with and without $T T X$ ) was statistically significant (P < 0.001 ) when tested with Student's $t$ test.

+Slope of current-voltage relationship. Because of the abnormal sodium conductance not representative for membrane conductance (see text). 
periment in which instead of lowering of the $\mathrm{pH}$ we added $0.125 \mathrm{mmol} / \mathrm{l} \mathrm{HCT}$ to the bath before raising $[\mathrm{K}]_{\mathrm{e}}$ to $9 \mathrm{mmol} / \mathrm{l}$. HCT had no direct protecting effect.

Membrane Parameters in Solutions with Normal Extracellular Potassium Concentration. In the standard solution, the fibers had normal resting potentials of $-83.5 \pm 5.4 \mathrm{mV}(n=14)$ and $-85 \pm 3.2$ $\mathrm{mV}(n=7)$ in the presence and absence of $0.3 \mathrm{mg} / \mathrm{l}$ TTX, respectively (see Table 1 ). Current-voltage relationships determined with the three-microelectrode voltage clamp were significantly different from control. When in normal fibers the membrane potential is clamped to a value between $-80 \mathrm{mV}$ (resting potential) and $-65 \mathrm{mV}$ (threshold of the fast sodium current), an outward current flows that assumes a steady value about $10 \mathrm{msec}$ after the onset of the clamp pulse. In fibers from the patient, the membrane current flowed in the outward direction for about $20 \mathrm{msec}$ only and then reversed its direction to assume a steady negative value (Fig. 3).
When TTX was added to the bath, the flow of inward current was abolished, i.e., the time course of the current flow was indistinguishable from that in normal fibers. This finding suggests that in the fibers from the adynamia patient, depolarization slowly activates a sodium inward current that cancels-and even supersedes-the potassium outward current. A plot of the clamp currents flowing 55 msec after the onset of the voltage clamp pulses as a function of the clamp potential is shown in Fig. 4A. It illustrates the relatively large increase of the slow inward current with increasing depolarization.

When a normal muscle fiber is voltage-clamped to potentials less negative than $-64 \mathrm{mV}$, a fast and transient inward current is triggered, the excitatory sodium current responsible for the upstroke of the action potential. The three-microelectrode voltage clamp does not control the membrane potential along the whole fiber. During such pulses, therefore, a twitch is often elicited whereby the recording is terminated. Sometimes, in clamp pulses that exceed the threshold by not too much, the elec-

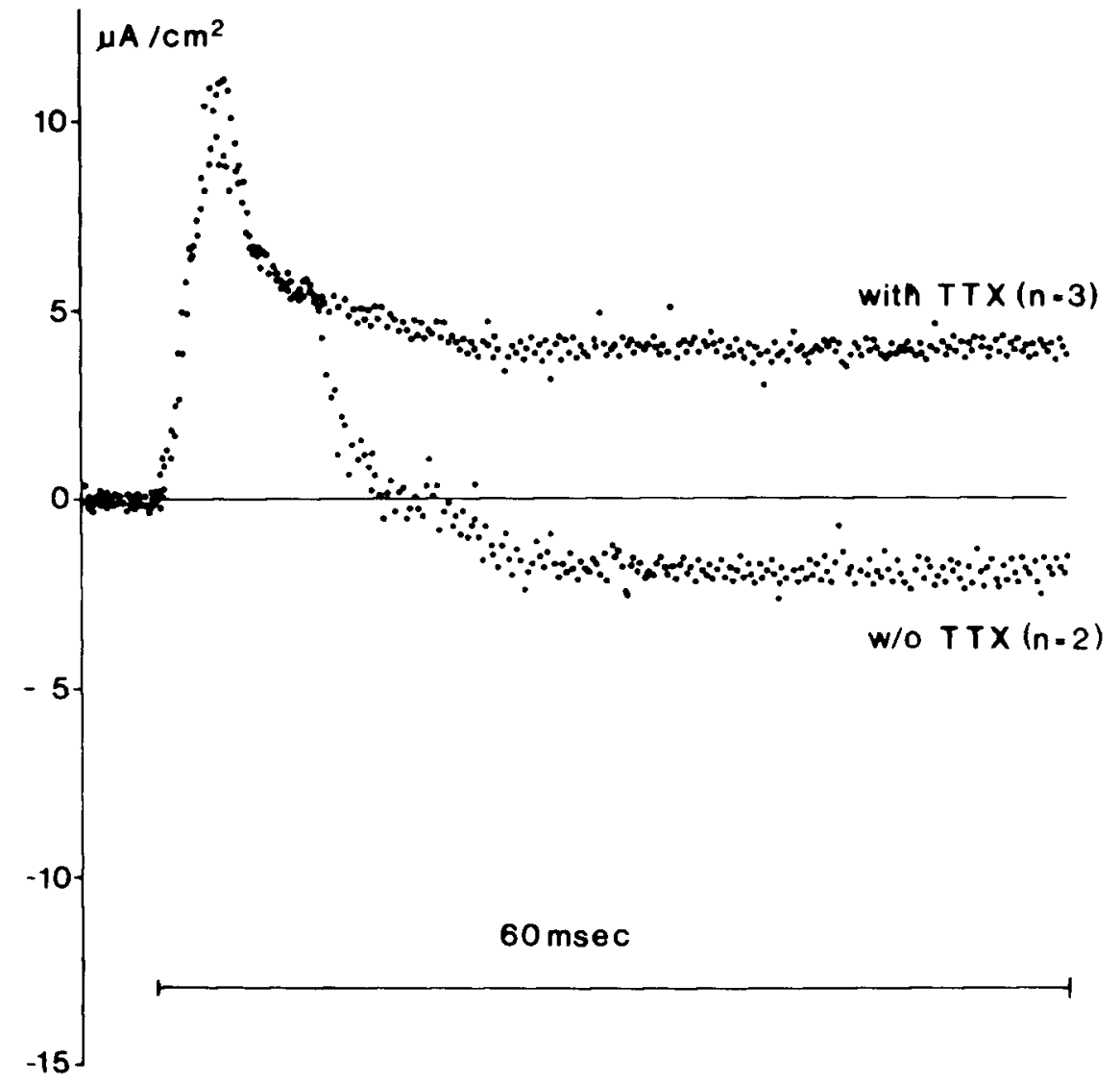

FIGURE 3. Time course of membrane current density in fibers from the adynamia patient during square voltage clamp pulses going from $-80 \mathrm{mV}$ to $-68 \mathrm{mV}$ for $60 \mathrm{msec}$. The traces are the digitized and averaged data from 3 fibers in the presence of $0.3 \mathrm{mg} / 1 \mathrm{TTX}$ (upper) and from 2 fibers in the absence of TTX (lower). The difference between the traces represents the slow natrium current. Current densities recorded from normal fibers would be identical to the upper trace, both in the presence and absence of TTX. 
trode positions remain stable, and the slow currents following the fast inward current can be recorded. Whenever this was the case with fibers from the patient, a fast and a slow inward current were observed. Both currents were abolished by $0.3 \mathrm{mg} / \mathrm{l}$ TTX. When voltage clamp pulses into this potential range were performed with normal fibers, the steady-state currents always flowed in the outward direction. ${ }^{21}$

It is well known that the membrane conductance, $g_{\mathrm{m}}$, of a muscle fiber is dependent on the membrane potential. To obtain values comparable among patients with various muscle diseases we adopted the standard procedure of determining $g_{\text {in }}$ from the slope of the current-voltage relationship at $-80 \mathrm{mV}$. This convention leads to spurious results in the case of episodic adynamia. The slope of the curve in Fig. $4 \mathrm{~A}$ is almost zero at $-80 \mathrm{mV}$, suggesting that the membrane conductance is extremely low. A better insight into the situation is obtained when the sodium conductance is abolished by the application of TTX so that only the potassium and chloride conductances play a role. The current-voltage relationships recorded from six fibers in the presence of TTX (Fig. 4A, asterisks) were indistinguishable from control curves obtained from normal human muscle in the presence or absence of TTX. ${ }^{21}$ In particular, the slope of the curve at $-80 \mathrm{mV}$ was normal. The simplest explanation of all these findings is that the passive potassium and chloride currents are normal in these fibers and that in the absence of T $\Gamma X$ an active sodium current is triggered by depolarization in the potential range only slightly below the resting potential. This active current reduces the net current flowing at $-80 \mathrm{mV}$ to almost zero, and therefore the slope conductance is low, although the membrane conducts large currents.

Membrane Parameters in Solutions with Increased Potassium Concentration. Figure $5 \mathrm{~A}$ illustrates an experiment in which we tested the effect of increased extracellular potassium on the resting potential. In the beginning, the bundle was bathed in

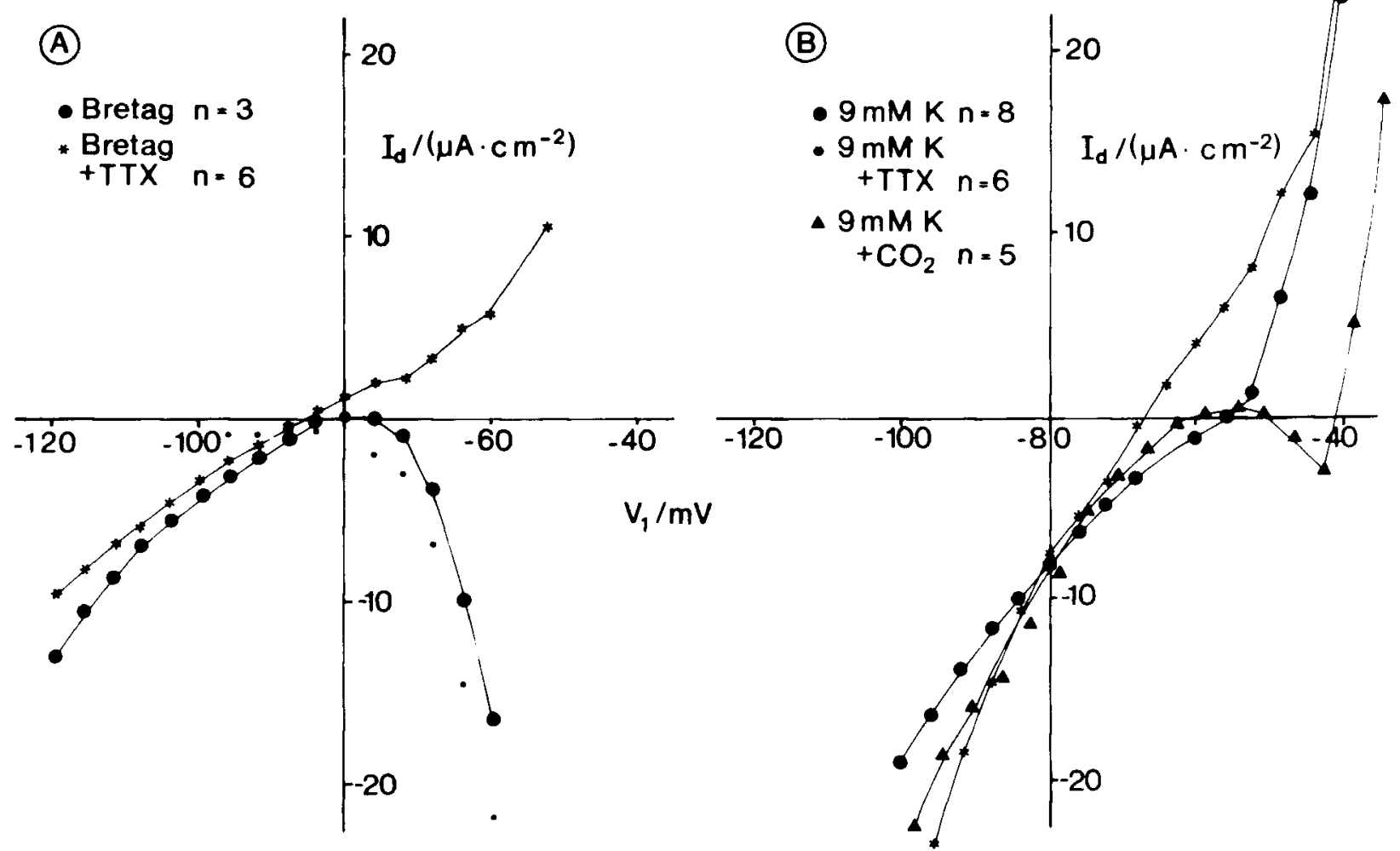

FIGURE 4. Current-voltage relationships of the muscle fiber membrane in adynamia episodica. The current amplitude at the end of square voltage clamp pulses of $60 \mathrm{msec}$ duration is plotted against the clamp potential. In A, the fibers were bathed in Bretag's standard

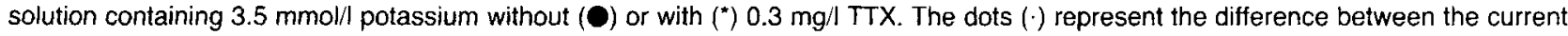
amplitudes in the presence and absence of TTX, i.e., the voltage dependence of the abnormal sodium current. In $\mathbf{B}$, the fibers were bathed in a solution containing $9 \mathrm{mmol} / /$ potassium without $(\mathbf{O})$ or with $\left(^{*}\right) 0.3 \mathrm{mg} / \mathrm{ITX}$. The curve marked by triangles $(\mathbf{\Delta})$ was recorded in a solution that contained $9 \mathrm{mmol} / \mathrm{l}$ potassium and no TTX and was gassed with a mixture of $40 \% \mathrm{CO}_{2}$ and $60 \% \mathrm{O}_{2}$. 
the standard solution with $0.3 \mathrm{mg} / 1 \mathrm{TTX}$ added to prevent the flow of the slow sodium current. The resting potential was negative to $-80 \mathrm{mV}$. When $[\mathrm{K}]$, was raised to $9 \mathrm{mmol} / \mathrm{l}$, the resting potentials decreased to $-67.5 \pm 3.7 \mathrm{mV}(n=13)$, a value similar to that adopted by normal fibers in this solution ( $-64.8 \pm 4.8 \mathrm{mV}, n=14$, dashed lines in Fig. 5). When a $7 \mathrm{TX}$-free bathing solution was introduced, many fibers began to twitch. Five minutes later this spontaneous activity had subsided enough for the membrane potentials to bc measured. Most fibers were now further depolarized so that the mean resting potential was $-57.3 \pm 5.4 \mathrm{mV}(n=$ 30). The statistical distribution of the values was normal both in the presence and absence of $\mathrm{TTX}$ so that Student's t-test of significance could be applied. The difference of the membrane potential values in the presence and absence of TTX was highly significant $(P<0.001)$. Such additional depolarization and twitching on removal of T TX was never observed in normal muscles. ${ }^{20}$
In a similar experiment carried out with another bundle, we investigated the effect of $40 \%$ $\mathrm{CO}_{2}$ on the resting potential under the conditions in which the paralysis is prevented. In this experiment, illustrated in Fig. 5B, TTX was absent from the beginning so that all fibers depolarized to below $-64.8 \mathrm{mV}$ (dashed line) when $[\mathrm{K}]_{e}$ was raised to 9 $\mathrm{mmol} / \mathrm{l}$. Gassing the bathing solution with $40 \% \mathrm{CO}_{2}$ (and thereby lowering the $\mathrm{pH}$ to about 6.5 ) did not lead to an increase in the mean resting potential.

$\Lambda$ s regards the slow sodium current, currentvoltage relationships recorded in $9 \mathrm{mmol} / \mathrm{l}[\mathrm{K}]_{\mathrm{c}}$ (Fig. 4B) allowed an interpretation similar to that given for normal $[\mathrm{K}]_{\mathrm{c}}$. In a TTX-containing solution, the curve (astcrisks) had the same shape as the curve for normal fibers in high $[\mathrm{K}]_{\mathrm{c}} .{ }^{21}$ In particular, the slope at the resting potential was normal. The membrane conductance calculated from the slopes of 6 fibers was $376 \pm 69 \mu \mathrm{S} / \mathrm{cm}^{2}$. The corresponding figure evaluated in 6 fibers from a healthy control person was $321 \pm 46 \mu \mathrm{S} / \mathrm{cm}^{2}$. 'The curve te-
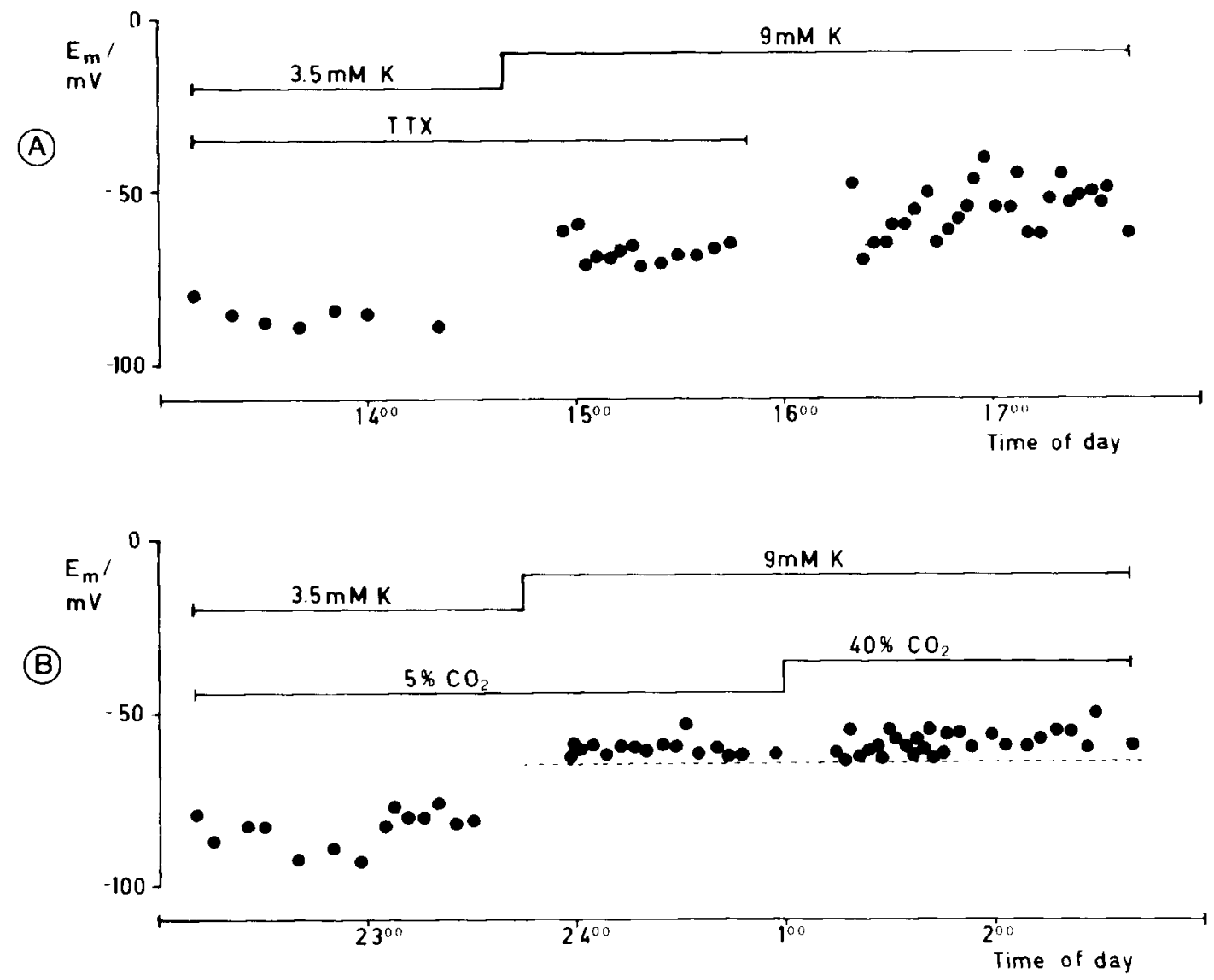

FIGURE 5. Dependence of the resting potential, $E_{\mathrm{m}}$, recorded in many fibers from the adynamia patient on various extracellular conditions In A, the bundle is in the standard solution containing $0.3 \mathrm{mg} / 1 \mathrm{TTX}$. When $[\mathrm{K}]_{\mathrm{e}}$ is increased to $9 \mathrm{mmol} / \mathrm{l}, E_{\mathrm{m}}$ assumes a value similar to the mean value assumed by normal human muscle fibers (dashed lines). When a 9 mmol/ $[K]_{e}$ solution without $T T X$ is flushed into the bath, $E_{\mathrm{m}}$ falls to a mean value of $-57.2 \mathrm{mV}$. In $\mathbf{B}$, another bundle is investigated, and the protocol differs from A in that no TTX is present from the beginning. At the end, the bathing fluid is gassed with a mixture of $40 \% \mathrm{CO}_{2}$ and $60 \% \mathrm{O}_{2}$; this has no effect on $E_{\mathrm{m}}$. 
corded in TTX-free solution (filled circles) deviated from the curve in TTX-containing solution in a direction that can be explained by the additional flow of a sodium current. This deviation was largest in the potential range between -80 and $-50 \mathrm{mV}$. Contrary to the curve in $3.5 \mathrm{mmol} / /[\mathrm{K}]_{\mathrm{e}}$, the curve in $9 \mathrm{mmol} / \mathrm{l}[\mathrm{K}]_{\mathrm{c}}$ did not have a region of negative slope. This might be due to the fact that an increase in $[\mathrm{K}]_{\mathrm{e}}$ increases the membrane conductance for potassium to a degree that the potassium outward current effectively cancels the slow sodium inward current.

We also recorded current-voltage relationships in the absence of TTX when the $\mathrm{pH}$ was lowered by gassing the bathing fluid with $40 \% \mathrm{CO}_{2}$ (Fig. $4 \mathrm{~B}$, triangles). The most obvious change was an increase in the slow sodium current between -50 and $-40 \mathrm{mV}$, which resulted in a range of negative slope. The reduction of the $\mathrm{pH}$ by 0.9 units did not significantly affect the slope conductance at the resting potential (see Table 1). Also in normal muscle, lowering of the $\mathrm{pH}$ from 7.4 to 6.5 did not change the slope conductance at the resting potential. (The absolute slope conductance values are lower than control for the muscle from the patient because of the abnormal sodium conductance, as explained above.) These results indicate that the chloride component conductance is not affected by this $\mathrm{pH}$ change.

The fast sodium current flowing during large clamp pulses was also increased in $40 \% \mathrm{CO}_{2}$. Since this was unexpected, we investigated the availability of the sodium current measuring the rate of rise of action potentials as described in Material and Methods. The maximal rate of rise of the action potentials starting from a holding potential of -90 $\mathrm{mV}$ was $25 \%$ higher $(\sim 500 \mathrm{~V} / \mathrm{sec})$ at $\mathrm{pH} 7.5(5 \%$ $\left.\mathrm{CO}_{2}\right)$ than at $\mathrm{pH} 6.5\left(40 \% \mathrm{CO}_{2}\right)$, in agreement with the literature. ${ }^{17}$ But with a holding potential of -60 $\mathrm{mV}$, the rate of rise was higher at $\mathrm{pH} 6.5(53 \mathrm{~V} / \mathrm{sec})$ than at pH $7.4(29 \mathrm{~V} / \mathrm{sec})$. Thus, a lowering of the $\mathrm{pH}$ decreased the sodium current of fibers having a normal resting potential but increased the sodium current of depolarized fibers.

Intracellular Sodium Activity, aNa. This parameter was investigated in muscle fibers from the patient and from three normal subjects. During the first 5-35 minutes after the impalement of a cell, usually a small drift of $\mathrm{Na}_{\mathrm{i}}$ towards lower values was observed that was most likely due to some injury of the cell membrane caused by the impalement. The following data were recorded after $\mathrm{aNa}_{\mathrm{i}}$ had reached a steady level. When a fiber bundle from the patient was in the standard solution, $\mathrm{aNa}_{i}$ was $6.9 \pm 1.0$ $\mathrm{mmol} / \mathrm{l}(n=10)$ and the resting potential, $E_{\mathrm{m}}$ was $-84.6 \pm 2.8 \mathrm{mV}$. Control values from a normal subject were very similar $\left(\mathrm{aNa}_{\mathrm{i}}=6.6 \pm 0.9 \mathrm{mmol} / \mathrm{l}\right.$; $E_{\mathrm{m}}=-84.2 \pm 2.7 \mathrm{mV}, n=8$ ). An elevation of $[\mathrm{K}]_{\mathrm{e}}$ to $7 \mathrm{mmol} / \mathrm{l}$ produced the same amount of membrane depolarization in the fibers from the patient and the normal subject and was without any effect on $\mathrm{aNa}_{\mathrm{i}}$ (Fig. 6). In retrospect it appears that the application of $7 \mathrm{mmol} / \mathrm{l}[\mathrm{K}]_{\mathrm{c}}$ to the bundle from the patient was too short-lasting, because the depolarization had not yet reached a steady level (Fig. $6 \mathrm{~B})$. Thus, with longer exposure, even at $7 \mathrm{mmol} / \mathrm{l}$ $[\mathrm{K}]_{\mathrm{e}}$ the fibers from the patient might have shown the abnormal behavior that was clearly visible when $[\mathrm{K}]_{\mathrm{e}}$ was raised to $10 \mathrm{mmol} / \mathrm{l}:$ (1) the depolarization was much greater than in the control fibers (Fig. $6 \mathrm{~A}$ ), indicating that high $[\mathrm{K}]_{\mathrm{e}}$, in addition to shifting the potassium equilibrium potential, had another depolarizing effect, i.e., activation of an inward current; (2) $\mathrm{aNa}_{\mathrm{i}}$ increased, indicating that the inward current was carried by sorlium; and (3) the membrane did not repolarize when the standard solution was reapplied, suggesting that the inward current was not inactivated. Only when 3 $\mu \mathrm{mol} / \mathrm{l} \mathrm{T} \mathrm{IX}$ were added to the standard solution $\operatorname{did} E_{\mathrm{m}}$ and $\mathrm{aNa}_{\mathrm{i}}$ return to normal. The rise of $\mathrm{aNa}_{\mathrm{i}}$ on application of $10 \mathrm{mmol} / \mathrm{l}[\mathrm{K}]_{\mathrm{c}}$ was observed in all fibers from the patient and was never seen in control fibers. Figure 7 shows another experiment carried out with two other preparations. In a normal muscle fiber, the application of $10 \mathrm{mmol} / \mathrm{l}[\mathrm{K}]_{\text {. }}$ had similar effects in the absence and in the presence of TTX (Fig. 7A): the membrane depolarized to about $-65 \mathrm{mV}$, and $\mathrm{aNa}_{\mathrm{i}}$ was unaffected. $\Lambda \mathrm{p}-$ plication of $0 \mathrm{mmol} / \mathrm{l}[\mathrm{K}]_{\mathrm{e}}$ produced the expected upward deflection of the $\mathrm{aNa}_{i}$ trace, indicating that the microelectrode was functioning well. Figure 7B illustrates that in a fiber from the patient the application of $10 \mathrm{mmol} / \mathrm{l}[\mathrm{K}]_{\mathrm{e}}$ in the absence of T TX produced an abnormally large depolarization and an increase in $\mathrm{aNa}_{\mathrm{i}}$, whereas, in the presence of I"IX, the depolarization had the amount expected from the Goldman equation, and $\mathrm{aNa}_{\mathrm{i}}$ returned to normal.

\section{DISCUSSION}

The present results are very similar to those obtained from another patient who had adynamia episodica with myotonia and differ from the results from the patient who had adynamia episodica without myotonia. ${ }^{24}$ 
The results confirm the earlier finding that the resting potential of the muscle fibers is high when the potassium concentration in the bathing medium, $[\mathrm{K}]_{e}$, is normal. This and the new finding of a normal resting sodium activity indicate that there is no defect in the $\mathrm{Na} / \mathrm{K}$ pumps in this disease. The results further confirm that, in adynamia episodica with myotonia, elevation of $[\mathrm{K}]_{e}$ produces an abnormally large and persistent depolarization of the muscle fiber membranes. The depolarization is large enough to cause inexcitability in most of the fibers but not large enough to reach the threshold for contracture. The inexcitability explains the decrease of isometric force observed in vitro and, since serum potassium may easily rise to $7-9 \mathrm{mmol} / \mathrm{l} \mathrm{dur}$ ing paralytic episodes, ${ }^{30}$ also the immediate mechanism of clinical adynamia.

Current-voltage relationships recorded at high $[\mathrm{K}]_{\mathrm{e}}$ in fibers from the earlier ${ }^{24}$ adynamia patient with myotonia had shown that the reason for the abnormally large depolarization is the flow of an abnormal inward current carried by sodium. We
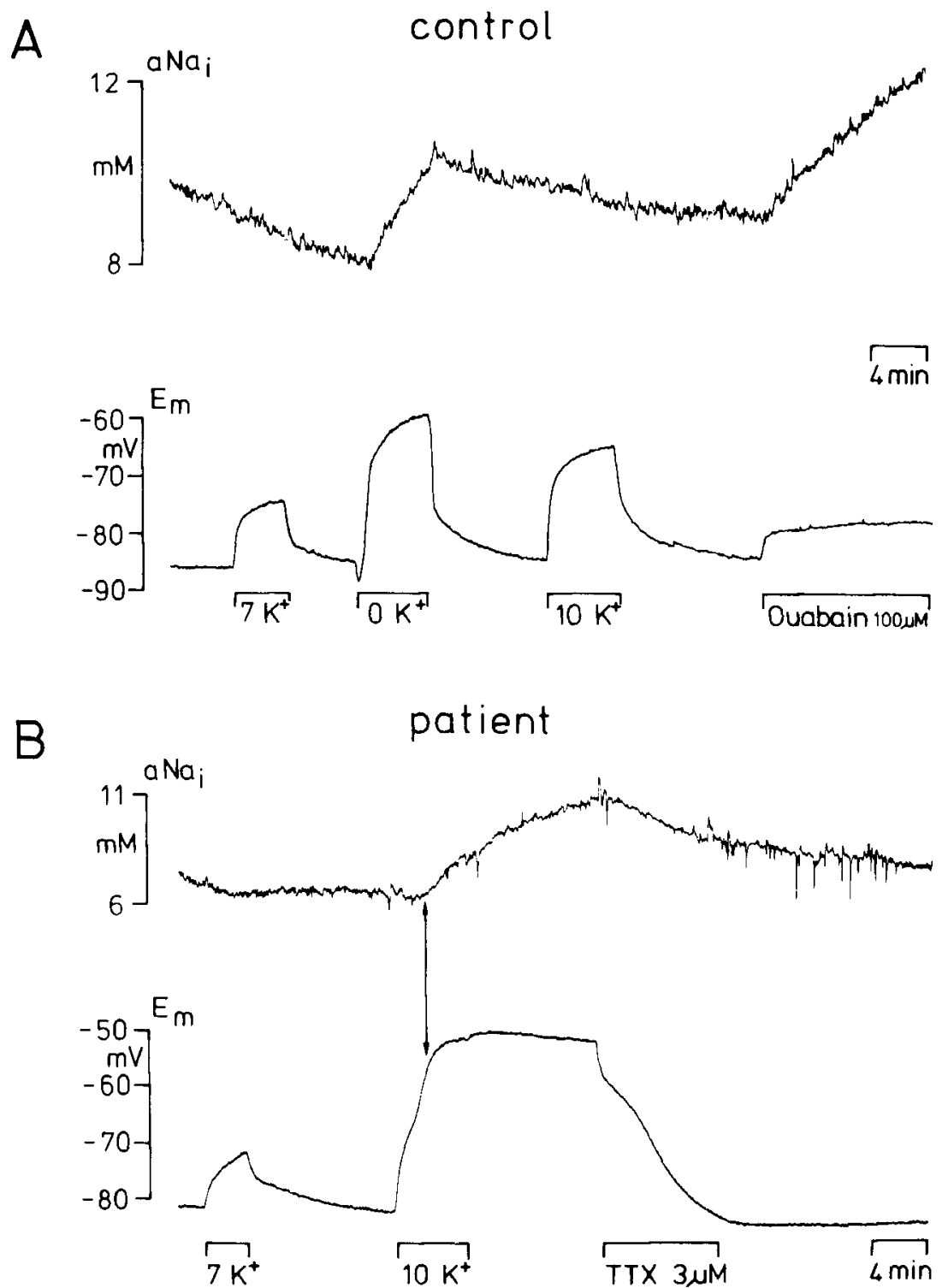

FIGURE 6. Recordings of the intracellular sodium activity, $\mathrm{aNa}_{\mathrm{i}}$, and the resting potential, $E_{\mathrm{m}}$, in fibers from a healthy control person (A) and the adynamia patient (B). $[\mathrm{K}]_{\mathrm{e}}$ is $3.5 \mathrm{mmol} / /$ unless otherwise indicated. In the presence of $10 \mathrm{mmol} /[\mathrm{K}]_{\mathrm{e}}$, the fiber from the patient shows an abnormally large depolarization and, associated with it, an increase of $\mathrm{aNa}_{\mathrm{i}}$. The applications of solutions containing $0 \mathrm{mmol} / \mathrm{l}[\mathrm{K}]_{\mathrm{e}}$ or $100 \mu \mathrm{mol} / \mathrm{l}$ ouabain in A are standard tests for the $\mathrm{Na}$ sensitivity of the microelectrode based on the presumption that these changes block the $\mathrm{Na} / \mathrm{K}$ pump. The large depolarization induced in the control fiber by the K-free solution is caused by the inhibition of the electrogenic $\mathrm{Na} / \mathrm{K}$ pump and by changes of the $\mathrm{Na}$ and/or $\mathrm{K}$ permeabilities of the fiber membrane. For further details see text. 


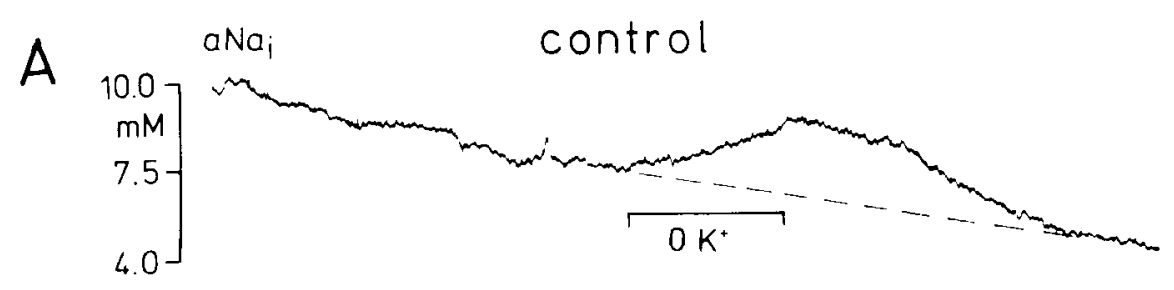

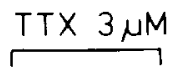
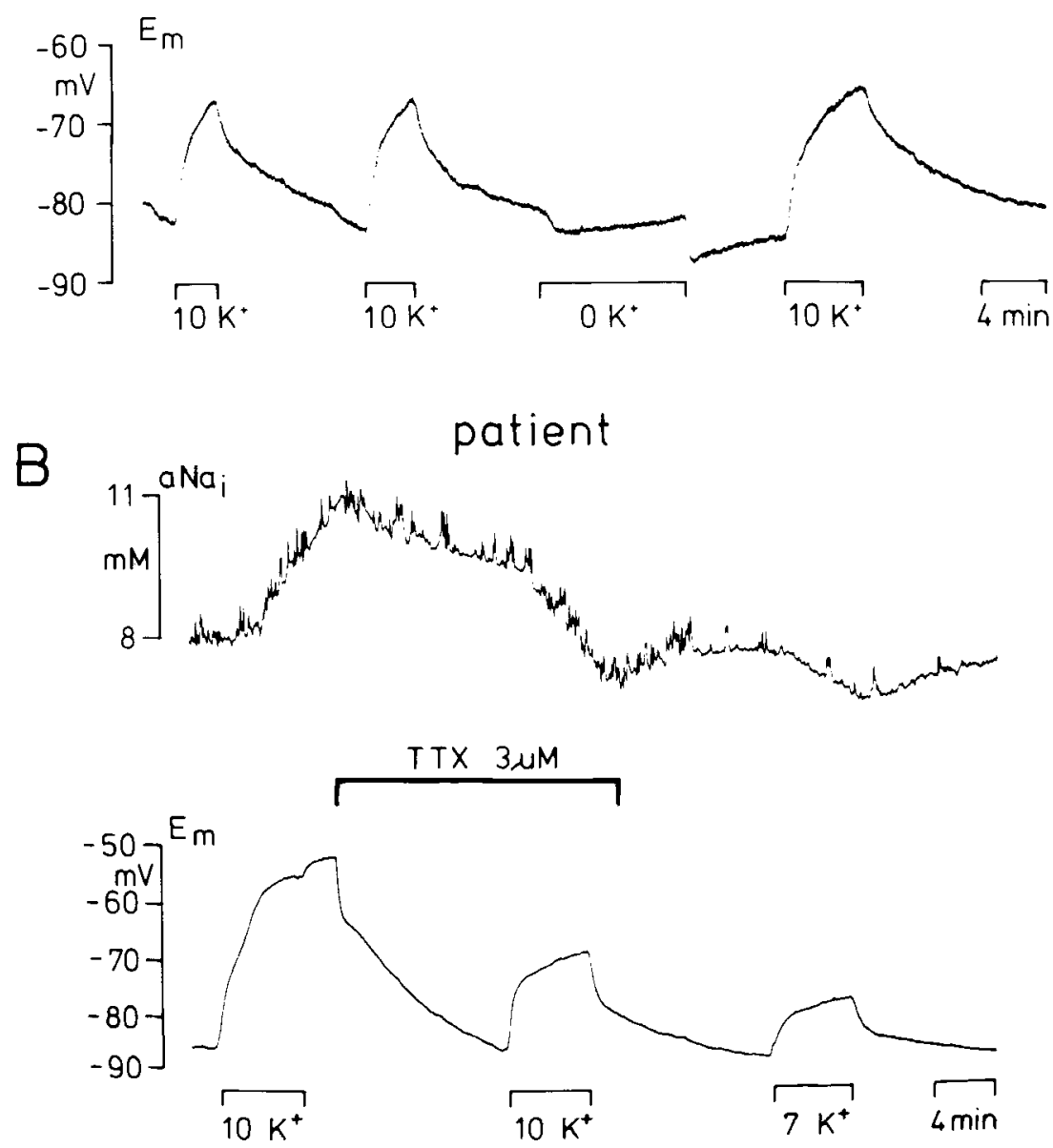

FIGURE 7. Recordings as in Fig. 6 from two other fibers. Again, the major result of the experiment is the abnormally large depolarization and the associated increase in $\mathrm{aNa}_{i}$ seen in the patient's fiber when $[\mathrm{K}]_{\mathrm{e}}$ is raised to $10 \mathrm{mmol} / \mathrm{l}$. Abnormal depolarization and increase of $\mathrm{aNa}_{\mathrm{i}}$ do not occur in the presence of TTX.

have now shown that this current is slowly activated by even slight membrane depolarization, and that in contrast to the fast sodium current, this current is not inactivated. By the additional measurement of the intracellular sodium activity, we have demonstrated more conclusively than with the mere application of TTX that this current is indeed carried by sodium. This makes other possible explanations of this current ${ }^{34}$ very unlikely. We suppose that other depolarizing influences on the muscu- lature of these patients, such as extreme cold or the use of muscle relaxants, may also trigger this abnormal sodium current and thus lead to adynamia, a supposition that is in agreement with the clinical experience.

The experiments show that the existence of noninactivating sodium channels in muscle fiber membranes may lead to an abnormal function of the musculature. Such non-inactivating channels could either belong to an altered channel-type resulting 
from a defect in the genetic code for sodium channels or to a physiological type recently detected in normal mammalian neurones. ${ }^{35}$ In the latter case, these sodium channels would have to be abnormal in number. It is worth noting that lidocaine, which is known to block the fast sodium channels, did not block the non-inactivating sodium channels in Purkinje cells. ${ }^{37}$ Tocainide and mexiletine, lidocaine derivatives that are very effective in the treatment of paramyotonic stiffness and weakness, do not prevent attacks of hyperkalemic weakness in paralysis periodica paramyotonica. ${ }^{29,30}$ Apparently, the effect of the local anesthetics is linked to the presence of a functioning inactivation gate. In contrast, T $\Gamma X$ also blocked the non-inactivating channels in the preparations from the adynamia patients.

It is interesting that a lowering of the $\mathrm{pH}$ of the bathing fluid antagonized the force decrease caused by increased $[\mathrm{K}]_{\mathrm{e}}$, and that this effect was not based on an increase in the resting potential but on an appropriate change of the inactivation characteristic ( $h_{\infty}$ curve) of the sodium channels. The decrease of inactivation is an effect of increased extracellular $\mathrm{H}^{+}$concentration described in several tissues. $^{7.17}$ Increase of the extracellular calcium concentration, known to alleviate paralytic attacks, is probably effective by a similar mechanism, namely a binding of these ions to external sites of the membrane. ${ }^{17}$ Gassing the bathing fluid with $40 \% \mathrm{CO}_{2}$ is known to lower both the extra- and the intracellular $\mathrm{pH}$ of a submerged tissue, ${ }^{1}$ whereas addition of $\mathrm{HCl}$ to the bathing fluid lowers the extracellular $\mathrm{pH}$ without an immediate effect on the intracellular $\mathrm{pH}{ }^{7.38}$ Since either method of lowering the $\mathrm{pH}$ had the same antiparalytic effect, the extracellular $\mathrm{pH}$ seems responsible for it.

It is well known that the serum potassium rises to high values as a consequence of heavy exercise, and yet adynamia patients do not experience paralytic attacks during the work. Our results suggest that the work-induced lowering of the $\mathrm{pH}$ may mediate this effect. The protective effect of slight exercise during an on-coming attack may not necessarily be explained the same way because the $\mathrm{pH}$ shift introduced in our experiments was much greater than that observed in ${ }^{31} \mathrm{P}$ nuclear magnetic resonance spectroscopy of forearm muscles during light work. ${ }^{22}$ Other factors, like the hyperpolarizing effect of the catecholamines, may play a role." The observation that muscle rest per se may lead to weakness of single muscle groups ${ }^{36}$ is as yet completely unexplained.

\section{REFERENCES}

1. Aickin CC: Direct measurement of intracellular $\mathrm{pH}$ and buffering power in smooth muscle cells of guinea-pig vas deferens. I Physiol (Lond) 349:57 1-585, 1984.

2. Becker PE: Myotonia Congenita and Syndromes Associated with Myotomia. Stuttgart, Thieme, 1977.

3. Bekény G, Hasznos T, Solti F: Über die hyperkaliämische Form der paroxysmalen Lähmung. Zur Frage der Adynamia episodica hereditaria. Dtsch $Z$ Nervenheilkunde 182 : $92-118,1961$

4. Bradley WG: Adynamia episodica hereditaria: clinical, pathological and clectrophysiological studies in an affected family. Brain 92:345-378, 1969.

5. Bretag AG: Synthetic interstitial fluid for isolated mammalian tissue. Life Sci 8:319-329, 1969.

6. Buchthal F, Engbaek L., Gamstorp I: Paresis and hyperexcitability in adynamia episodica hereditaria. Neurology (Minneap) 8:347-351, 1958 .

7. Caldwell PC: Studies on the internal pH of large muscle and nerve fibres. J Physiol (Lond) 142:22-62, 1958.

8. Carson MH, Pearson CM: Familial hyperkalemic periodic paralysis with myotonic features. I Pediatr 64:853-865, 1964

9. Clausen $\mathrm{T}$, Wang $\mathrm{P}$, Orskov $\mathrm{H}$, Kristensen $\mathrm{O}$ : Hyperkalemic periodic paralysis. Relationships between changes in plasma water, clectrolytes, insulin and catecholamines during attacks. Scand J Clin Lab Invest 40:21 l-220, 1980.

10. Drager GA. Hammill JF, Shy GM: Paramyotonia congenita. Arch Neurol Psychiatry 80:1-9, 1958.

11. French EB, Kilpatrick R: A variety of paramyotonia congenita. I Neurol Neurosurg Psychiatry 20:40-46, 1957

12. Gamstorp I: Adynamia episodica hereditaria. Acta Paediatr Stockholm (Suppl) 108:1-126, 1956.
13. Cirafe $P$, Ballanyi $\mathrm{K}$, Küther $\mathrm{G}$ : Intracellular $\mathrm{Na}^{+}$activity in normal human intercostal muscle and in one case of hyperkalemic periodic paralysis. Pfluegers Arch 403:R58, 1985.

14. Grafe P, Rimpel J, Reddy MM, ten Bruggencate (x: Changes of intracellular sodium and potassium ion concentration in frog spinal motoncurons induced by repetitive synaptic stimulation. Neuroscience 7:3213-3290, 1982.

15. Helweg-Larsen HF. Hauge M, Sagild U: Hereditary transicnt muscular paralysis in Denmark: genetic aspects of family periodic paralysis and family periodic adynamia. Acta Genet Stat Mod 5:263-281, 1955.

16. Heuser M, Pongratz D, Struppler A, Mittelbach F: Familiäre hyperkaliämische periodische Lähmung. Z EEG EMC; $5: 150-158,1974$.

17. Hille B: Ionic channels in Excitable Membrames. Sunderland, MA, Sinauer, 1984.

18. Hoff van't $W$ : Familial myotonic periodic paralysis. Q / Med $31: 385-403,1962$.

19. Krull GH, Leijnse B, Viëtor WPJ, Vlieger M, Braak JWC, Gerbrandy J: Myotonia produced by an unknown humoral substance. Lancet ii:668-672, 1966.

20. Kwiecinski $H$, I,ehmann-Horn $\mathbf{F}$, Rüdel $\mathbf{R}$ : The resting parameters in human intercostal muscle at low, normal, and high extracellular potassium. Muscle Nerie 7:60-65, 1984.

21. Kwieciński H, Lehmann-Horn F, Rüdel R: Membranc currents in human intercostal muscle at varied extracellular potassium. Muscle Nerie 7:465-469, 1984.

22. Lehmann-Horn F, Höpfel D, Rüdel R, Ricker K, Küthes $G$ : In vivo P-NMR spectrocopy: muscle energy exchango in paramyotonia patients. Muscle Neree 8:606-610, 1985.

23. Lehmann-Horn F, Rüdel R, Dengler R, Lorković H, Haass 
A, Ricker $\mathrm{K}$ : Membrane defects in paramyotonia congenita with and without myotonia in a warm environment. Muscle Nere 4:396-406, 1981 .

24. I ehmann-Horn F, Rüdel R, Ricker K. Lorković H. Dengler R, Hopf HC: Two cases of adynamia episodica hereditaria in vitro investigation of muscle cell membrane and conraction parameters. Muscle Nerve 6:113-121, 1983.

25. I.ewis ED. Griggs RC. Moxley RT: Regulation of plasma potassium in hyperkalemic periodic paralysis. Neurology (Minneap) 29:113]-1137, 1979.

26. McArdle B: Adynamia episodica hereditaria and its treatment. Brain 85:12 1-148, 1962.

27. MeComas AJ, Mrozek K, Badley WG: The nature of the electrophysiological disorder in ad ynamia cpisodica. J Neurol Netrosurg Psychiatry 31:448-452, 1968.

28. Meulen van der JP, Gilbert GJ, Kane CK: Familial hyperkalemic paralysis with myotonia. $N$ Engl J Med 264:1-6, 1961 .

29. Ricker K. Böhlen R. Rohkamm R: Different effectiveness of tocainide and hydrochlorothiazide in paramyotonia congenita with hyperkalemic episodic paralysis. Neurology (NY) $33: 1615-1618,1983$.

30. Ricker K. Rohkamm R. Böhlen R: Adynamia episodica and paralysis periodica paramyotonica. Neurology (NY) 36: $682-686.1986$.
31. Rigrss JE, Griggs RC. Moxley RT. Lewis ED: Acute effects of acetazolamide in hyperkalemic periodic paralysis. Neu rology (NY) 31:725-729, 1981.

32. Rüdel R, Lehmann-Horn F, Ricker K, Küther (;: Hypokalemic periodic paralysis: in vitro investigations of muscle fiber membrane parameters. Muscle Nerie 7: 1 10-120, 1984.

33. Rüdel R, Ricker K: The primary periodic paralyses. TINS $8: 467-470,1985$

34. Ruff RI, Gordon AM: Disorders of muscle: the periodic paralyses, in Andreoli TE, Hoffman JF, Fanestil DD, Schulty SG (eds): Physiology of Membrane Disorders, 2nd ed. New York. Plenum Press, 1986. pp 825-839.

35. Stafstrom CE, Schwindt PC, Chubb MC, Crill WE: Properties of persistent sodium conductance and calcium conductance of layer $V$ neurons from cal sensorimotor cortex in vitro. J Neurophysiol 53:153-170, 1985.

36. Subramony SH, Wee AS: Exercise and rest in hyperkalemic periodic paralysis. Neurolog (NY) 36:173-177, 1986.

37. Sugimori M, I.linas R: Lidocaine differently blocks fast and slowly inactivating sodium conductance in Purkinje cells: an in viro study in guinca pig cerebellum using iontophoretic glutamic acid. Sor Neumsri abstr 6:468, 1980.

38. Thomas RC: The effect of carbon dioxide on the intracellular $\mathrm{pH}$ and buffering power of squid neurones. I Physiol (Lond) $255: 717-735,1976$. 